\title{
The Cara Syria programme - combining teaching of English for academic purposes and academic and research skills development
}

Article

Accepted Version

Brewer, S. ORCID: https://orcid.org/0000-0002-3687-6202 and Whiteside, K. (2019) The Cara Syria programme - combining teaching of English for academic purposes and academic and research skills development. Language Learning in Higher Education. ISSN 2191-6128 doi:

https://doi.org/10.1515/cercles-2019-0010 Available at https://centaur.reading.ac.uk/102717/

It is advisable to refer to the publisher's version if you intend to cite from the work. See Guidance on citing.

Published version at: http://dx.doi.org/10.1515/cercles-2019-0010

To link to this article DOI: http://dx.doi.org/10.1515/cercles-2019-0010

Publisher: De Gruyter

All outputs in CentAUR are protected by Intellectual Property Rights law, including copyright law. Copyright and IPR is retained by the creators or other copyright holders. Terms and conditions for use of this material are defined in the End User Agreement. 


\section{www.reading.ac.uk/centaur}

\section{CentAUR}

Central Archive at the University of Reading

Reading's research outputs online 
Sarah Brewer and Karin Whiteside

Contributing authors:

Mr Mohamad Ousamaa Alabdulaa, Cara Syria Programme, Cara, London, UK

Dr Melhem Alabdullah, Cara Syria Programme, Cara, London, UK

Dr Samir Alabdullah, Cara Syria Programme, Cara, London, UK

Dr Manaf Aldakhil, Cara Syria Programme, Cara, London, UK

Dr Abdulnaser Aljasem, Cara Syria Programme, Cara, London, UK

Dr Wissam Aldien Aloklah, Cara Syria Programme, Cara, London, UK

Dr Taiseer Mohammad Barmu, Cara Syria Programme, Cara, London, UK

Dr Adnan Rashid Mamo, Cara Syria Programme, Cara, London, UK

Dr Iman Sarmini, Cara Syria Programme, Cara, London, UK

\title{
The Cara Syria Programme - combining teaching of English for Academic Purposes and academic and research skills development
}

\begin{abstract}
The Cara Syria Programme has been developed to support Syrian academics who have had abandon their academic positions due to the conflict in Syria and who have seen their careers compromised as a result. The Programme offers a means to re-establish their academic identities and develop new skills through participation in the learning activities and workshops provided on the Programme itself and through potential research collaborations with academics in universities in the UK. A key element is the training in English for Academic Purposes (EAP), which is delivered in weekly online lessons and intensive language workshops in Turkey. Both the online teaching and the workshops are staffed by volunteers working in language teaching and specifically in English for Academic Purposes. One of the core principles of this teaching is to pitch content in a way that is intellectually motivating and relevant in terms of the participants' academic identities, but scaffolded to take into account language proficiency levels, which can be as low as CEFR A1. Over the last eighteen months the technology, administrative structures, and language materials suitable for learners at all levels between $\mathrm{A} 1$ and $\mathrm{C} 1$ have been developed, and the process mapped to ensure sustainability.
\end{abstract}


Keywords: English for Academic Purposes (EAP), Syrian academics, online teaching, workshops, academic skills, blended learning; research

Dr Sarah Brewer, International Study and Language Institute, University of Reading, UK s.m.brewer@reading.a.cuk (for correspondence)

Dr Karin Whiteside, International Study and Language Institute, University of Reading, UK k.whiteside@reading.ac.uk

\section{Context}

The language teaching initiative described in the report below is a component of a larger programme launched by Cara (the Council for At-Risk Academics), a UK-based charity founded in 1933. Cara's work was initially with academics suffering persecution as a result of the rise of Fascism, but the charity has continued to offer support to academics across the world who are in some way at risk. Support is often provided in the form of a Cara Fellowship enabling an academic to continue their research in another, safer, environment, but in the case of the Syria Programme, the support has also included a programme of workshops and language tuition. The academics who have joined the Programme are all displaced from their homes and universities in Syria and are now living in Turkey. Having been driven to relinquish their academic roles, they have not only lost their livelihoods, but are also at risk of losing their academic skills, which carries with it the larger risk of the loss of Syria's intellectual capital.

The Cara Syria Programme was launched in 2012 in partnership with the 117 universities that make up the Cara Scholars at Risk UK Universities Network. The network provides research opportunities for academics within the UK, but in 2016, with no end to the crisis in Syria in sight, Cara extended the programme to support academics in exile in the region. The overall aim has been to "sustain, strengthen and connect Syrian academics whilst in exile in the region, as a group that is vital to the future of Syria" ("Sustaining Syria's Intellectual Capital", 2016). The design of the Programme has emerged out of the Cara Iraq Programme (2006-12) which had a similar remit, but which did not provide a language learning strand. This strand has proved to be an essential component in the Programme, contributing to the sustained language development of the participants, thus providing a potential pathway to research collaboration with academics in institutions in the UK. However, it is one strand in what is a more complex programme with another key component, Academic Skills Training, which is also provided by means of workshops, supplemented with 
webinars delivered by academic specialists in the UK from a number of different institutions. The combination of the language learning strand focusing on English for Academic Purposes (EAP) and the Academic Skills Development (ASD) strand has been an innovation for Cara and appears to have had a powerful motivational impact on the academic participants.

\section{Activity}

The aim of the EAP strand of the Syria Programme is to provide a strong language base for Syrian academics, so as to allow them to engage academically in a wider, English speaking context. Cara as an organisation had had no previous experience of collaborating with language specialists, but following a round table meeting in 2016, contact was made with BALEAP, the global forum for EAP professionals, and a call went out to the EAP community. This resulted in 11 institutions sending representatives to a meeting in the International Study and Language Institute (ISLI) at the University of Reading, co-chaired by Kate Robertson (Cara's Middle Eastern Consultant) and Ros Richards, Head of ISLI.

BALEAP subsequently provided a pool of tutors for online teaching, a core element of the programme, but working with 11 institutions proved unwieldy and so when the first visit was arranged, members of five institutions (six people) took part and travelled to Istanbul to meet and test the first applicants in Phase 1 of the programme on a face-to face basis All applicants to the programme have to be established academics, having held an academic post in Syria, but at this stage, little was known of their linguistic capabilities. This was an opportunity to meet and interview participants and to use standard placement tests as used by UK universities for assessing the English levels of international students. In this case, the tests used were a reading test with short answer questions, a writing task, a multiple choice vocabulary and grammar test and an interview to assess speaking and listening skills. It was generally the case that in spoken language performance, the participants demonstrated higher competence than in the output of the reading and writing tests. Scores ranged from $2.0-6.0$ in IELTS terms (CEFR A1-B2).

As a basis for planning the future programme this first visit was essential, but it was clear that paper-based assessment would not be feasible for the ongoing work of assessing and placing new participants joining the Cara programme. We have therefore subsequently moved to testing online, using a pilot version of the University of Edinburgh's online English test. This includes an interview, a writing task and a cloze test and has been used successfully to provide placement scores to allow participants to be allocated to an appropriate group. 


\section{Building a blended programme}

From the outset, it had been decided to provide a blended language course with a bespoke website for tutors and participants, weekly online lessons using Adobe Connect, and incountry (Turkey) workshops to provide intensive language input. Following the initial testing, the participants were put into three levels: low (A1-low A2), middle (high A2-low B1) and high (high B1-C1). Each of these was co-ordinated by a different university: Sheffield Level 1 (low); Reading - Level 2 (middle); Edinburgh - Level 3 (high). As a basis for regular teaching for Levels 1 and 2, the co-ordinator at the University of Sheffield was able to arrange for tutors to use the Cambridge-published textbook, Empower (Doff et al. 2015), which provides not only a paper textbook, but also a substantial online resource. Tutors in the three groups are drawn from teaching staff at each institution and from a wider pool of volunteers, mainly the BALEAP community of teachers of English for Academic Purposes. Syrian academic participants are matched with a tutor, allocated a time when they can enter an Adobe Connect room and meet once a week. The Syrian participant commits to studying a minimum of four hours a week; a personal learning plan is drawn up and agreed by tutor and participant; and lessons are recorded, with the link to the recording being sent to the participant so that they can review the lesson. Homework is set (though the circumstances of the participants mean that they are not always in a position to complete it) and attendance is recorded.

\section{Online lessons - developing language competence and providing continuity}

The weekly online tutorials are a key element of the programme, ensuring continuity of contact and a providing the means for sustained language development. However, as might be expected, teaching online is not without its difficulties, some of which are technological and some pedagogical. Internet connections are generally good enough, but individual participants' environments are varied and the technology does periodically break down; pedagogically, using teaching materials through the Adobe Connect pods is not as familiar to many tutors as more frequently used classroom technology, such as smartboards and visualisers. Despite these difficulties, the contact through Adobe seems generally to be recognised by the participants as providing a valued means of building their language competence. Evidence of this evaluation of the online tutoring was gathered in a reflective exercise carried out in April 2018 with a group of participants from Levels 1 and 2 who had joined the programme in February 2017. The academics involved considered aspects of their language learning to try to establish the relative effectiveness of different modes of delivery 
and their response to the process. The feature that was most commented on was the "continuity of learning" that weekly lessons brought, one participant seeing this as providing "continuous communication and non-stop learning of language". Participants also valued "flexibility", "speed" and "variety", and the provision of "fast and accurate information". A further feature of the online lessons that was highlighted was the opportunity the online lessons afford of communicating with a native speaker of English. The value of this was variously described as giving good listening practice and as a means of getting correction for pronunciation.

These comments reflect the views of participants from Level 1 and Level 2 groups. Their tutors have engaged in conversation, worked on the Empower materials, introduced learning materials of their own and responded to individual needs and requests as these have emerged over the last year. At Level 3, tutors and participants have been able to work at a more advanced level, identifying the specific needs of individual participants. One of the most proficient participants taking part in a focus group in September 2017 explained that for him, the "important step [...] was how I used the online sessions. I wrote an article and used those sessions to get the tutor to correct and improve the text. This article is going to be published soon. I also wrote a summary or a plan for two research proposals and was able to discuss them and correct them" (Focus group, Istanbul, September 2017).

An issue of developing a course that relies on volunteers to deliver lessons and indeed volunteers to set up, maintain and co-ordinate the delivery is that the time required to monitor and manage the programme is limited. This has been partly mitigated by effective use of technology, and the programme has been fortunate to have David Read, the Director of Technology at the University of Sheffield, as the technological lead. The importance of the technological infrastructure cannot be underestimated, as it is the means both to deliver the online learning and manage the running of the programme. Google docs have been used from the beginning to provide a secure platform to store data, provide documentation such as personal learning plans, and as a means of creating forms including a register form that goes out each week to tutors to fill in for their participants. Level co-ordinators still find it necessary to communicate on a regular basis with the tutors to collate information on participant progress and update tutors on other aspects of the programme, but the administrative basis as established with Google docs reduces the daily administrative workload.

\section{Face-to-face workshops in Istanbul}


The Syrian academics' engagement with the online lessons might have been reduced, had it not been for regular face-to-face workshops in Istanbul over the course of the programme. These have been held at approximately two monthly intervals and have evolved from separate workshops on English for Academic Purposes and Academic Skills Development (ASD) to a model where EAP and ASD have come together as one workshop spread over six days with some days devoted to EAP and some to ASD supported by EAP teachers.

It is important to note that from the beginning, Arabic-English interpreters have been employed to facilitate sessions at the workshops. The Level 1 academics have a limited range of language and in order to ensure that everyone has equal access to the information and expertise provided, it has been necessary to have sessions translated. In the very earliest language workshops, interpreters were used in sessions where the organisation of the language programme was explained to the participants and subsequently, interpreters have been used frequently for the ASD sessions and on occasion for EAP sessions.

In the first year of roll-out, each EAP level developed a distinctive pattern of delivery, targeting the needs of the participants and responding to the particular challenges of the programme. Chief among the latter was the changing constituency of the groups as some participants were not always able to join the workshops and new participants were being added to the groups. Even where participants attended on a regular basis, some were in a position to commit to more hours of study each week than others and the variation in individuals' environments also impacts on progress or lack of it. For many participants resident in Turkey there is also the more pressing need to learn Turkish.

Level 1 participants, as the group with the lowest level of proficiency (A1 or below to low A2), have concentrated on general English and, in common with Levels 2 and 3, have also focused on oral skills to a large extent, to capitalise on the opportunity to communicate in a group environment and activate their language over a sustained period of several days. Another common thread through all levels has been an effort to draw upon individual academics' knowledge in their field and to incorporate tasks facilitating communication about their subject area. This is clearly much more challenging at Level 1, but has been something that has been prioritised from the beginning as providing a strong motivation to learn and a means to boost confidence.

Level 2 participants' language level is at high A2 to low B1. A challenge in the workshops has been to pitch content in a way that is intellectually motivating and relevant in terms of their academic identities, but scaffolded to take into account language proficiency levels. Another challenge has been to ensure participants get as much value as possible from 
the small amount of face-to-face time (two to three days) that they get at the workshops. For the latter, a speaking-into-writing approach across a whole day of the workshop programme in which themes and language input are recycled for different purposes has proved useful. In this way, participants can feel as if they are gaining a wide range of language skills/knowledge without the cognitive overload of multiple themes and vocabulary sets.

Making links wherever possible to participants' own fields of academic activity and the academic research process helps with motivation and a sense of relevance, for example: 1 Focus on vocabulary development leading to participants' examination of texts from their discipline to identify useful lexical items and underline collocations and complex noun phrases.

2 Focus on the language of defining and explaining leading into participants preparing mini first-year lectures about key concepts from their discipline.

3 Focus on passive verb forms and signalling language for describing methods leading into to writing and speaking tasks in which participants communicate their own research methods. 4 Focus on the language of cause and effect within examples leading into participants writing short texts about cause-effect related issues within their own field.

5 Very carefully scaffolded introduction to a simple version of the Creating a Research Space (CARS) model (Swales 1990) leading to use of this as a template from which participants can write a brief summary of past or planned research.

Materials used for the workshops have been provided either by the teachers themselves (adapted from use in their institutions) or, in some cases, from textbooks written for lower intermediate levels.

Level 3 workshop sessions have drawn even more strongly on materials developed by teachers in their own institutions, but participants, who are at high B1 to low C2 level have been able to contribute more strongly, drawing on their previous experience and academic outputs. As with the other groups, work with the Level 3 participants has been focused on oral skills, with intensive work on language and vocabulary required to talk about their research interests either in the form of presentations or in communication with other academics.

As a means to improving their language skills, participants, unsurprisingly, identify different features in the workshops, compared to the online lessons, as being particularly beneficial to them as learners. In the reflective tasks carried out in April 2018, however, they did not identify the length and concentrated nature of the workshops as being particularly significant. The features that came particularly to the fore were learning "through body language, signs and facial expressions" and the "direct communication". This gives the 
participants the sense of "real participation" and that what is learnt "face-to-face in one hour is more than what I learn in two hours of e-learning or self-learning”. Taking part in the workshops appears as more strongly experienced and more vividly described. One participant wrote: "It gives courage and speeds up intellect. It also promotes discipline, team work and seriousness in carrying out the work". The theme of "courage" is taken up by another who said that the experience was the means of "breaking the fear barrier of learning".

\section{Summary of results/experience}

The Cara Syria Programme started with 21 Syrians in February 2017. Not all of these were able to continue, but many of them did and have been joined by between 40 to 50 other Syrian academics, with more applying each week. There is a palpable sense of confidence among those who have continued with the Programme and after a year of workshops and online tuition, participants are beginning to move up through the levels. The fifteen months that the Programme has run has seen the creation of an online portal that provides resources for participants and access to the webinars, as well as a means of communication. There is a solid administrative infrastructure based on Google docs and a strong team of co-ordinators and online tutors working with the Syrian academics. Teaching materials for each group continue to be developed and there is now some sharing of the materials between the levels at the workshops, but there remains further work to do to collect and collate materials so that they can be used for future similar programmes.

\section{Future prospects}

The Syria Programme relies on funding which has so far provided for up to two years of online tutoring and workshops. It is hoped that more funding will be secured so that both EAP and ASD training can be continued, particularly as it is likely that the outward flow of Syrian academics is likely to continue. There has been huge support from academics in the UK willing to contribute both to the EAP strand and the ASD strand on a voluntary basis and this, too, is likely to continue. A further strand of the Syria Programme has been a mapping and evaluation exercise, currently still underway and designed to ensure the sustainability of this Programme and the potential for replication in the future as need arises.

\section{References}

Cara (2016), "Sustaining Syria's intellectual capital: academics as agents for change”, Programme for Round Table, 9 and 10 June, Council for At Risk Academics, London, 
available at: www.cara.ngo/wp-content/uploads/2016/06/Round-Table-Final-Programme.pdf (accessed 10 April 2018).

Doff, Adrian, Craig Thaine, Herbert Puchta, Jeff Stranks, \& Peter Lewis-Jones. 2015.

Cambridge English Empower, A1-C1. Cambridge: Cambridge University Press.

Swales, John. 1990. Genre Analysis: English in academic and research settings. Cambridge:

Cambridge University Press.

\section{Biodata}

Dr Sarah Brewer is Head of English for Academic Purposes at the University of Reading's International Study and Language Institute. She has worked in the field of EAP since 2002, teaching international students at a range of different levels from Foundation to $\mathrm{PhD}$. In recent years, she has become particularly interested in being involved in initiatives to provide support to learners outside the immediate HE sector, either through mentoring or teaching EAP. 